\title{
doispontos:
}

\section{Foucault: atitude crítica e seu lugar na modernidade ${ }^{1}$}

\author{
Lara Pimentel Figueira Anastasio \\ Doutoranda no Departamento de Filosofia da Universidade de São Paulo (USP), São Paulo, Brasil \\ larapfa@gmail.com
}

\begin{abstract}
Monsier, d'après les immortels príncipes de 89, tous les hommes sont égaux em droits; donc je possède le droit de me mirer, avec plaisir ou déplaisir, cela ne regarde que ma conscience. Charles Baudelaire, Le miroir.
\end{abstract}

\begin{abstract}
Resumo: Tomando dois momentos em que Foucault interpreta a relação entre Kant e a Aufklärung, o primeiro, na conferência "O que é a Crítica?" (1978), e o segundo, nos dois artigos "O que é o Esclarecimento?" (1984), pretendemos mostrar de que modo seu olhar crítico evidencia uma compreensão prática da modernidade ao se inscrever na tradição da Aufklärung. Gostaríamos de mostrar como Foucault encontra nas bases da filosofia kantiana já uma atitude originária do pensamento crítico, prática que consiste fundamentalmente na decisão de não ser de tal forma governado. A principal consequência filosófica dessa postura é a construção de um pensamento estruturado no desenvolvimento de uma ontologia do presente, compreendida então como ontologia do devir.
\end{abstract}

Palavras-chave: Michel Foucault; Kant; modernidade; crítica; Aufklärung.

\section{Foucault: critical attitude and its place in modernity}

Abstract: This article examines Foucault interpretations of the relation between Kant and the Auklärung: first, in the conference "What is Critique?" (1978), and second in the articles called "What is Enlightenment?" (1984). We intend to show how his point of view evidences a practical understanding of modernity. Foucault found in the ground of Kantian philosophy an attitude that came from critical thinking, a practice that consists in the decision to not being governed like that. The main philosophical consequence of this posture is the construction of a thought structured in an ontology of the present, understood then as the ontology of becoming.

Keywords: Michel Foucault; Kant; modernity; critical; Aufklärung.

Como Foucault argumenta em As palavras e as coisas, tanto a filosofia pré-kantiana quanto a filosofia transcendental, que emerge como "acontecimento" que torna possível a abertura para a episteme moderna, resguardam um fundamento comum em relação ao problema da representação. Apesar da evidente ruptura, a filosofia kantiana, ao transformar o sujeito em fundamento do fenômeno (e assim delimitar a capacidade de representação), também não escapa do "Mesmo" que impede o surgimento da diferença na constituição do signo, como Foucault argumenta em sua hipótese da "analítica da finitude" e do aparecimento do "homem" como sujeito e objeto de saber em As palavras e as coisas ${ }^{2}$. Ambas as linhas filosóficas têm fundamento em uma origem unificadora, síntese prévia da experiência que é incapaz de escapar dos círculos criados pela representação ${ }^{3}$. 
Foucault não revê as conclusões quanto aos limites da representação quando se volta para a genealogia. Nesta última, o fundamento da representação também não escapa da concepção de mundo como um devir, ou, nos termos foucaultianos, do mundo como uma constante variação determinada pelos enfrentamentos de forças com diferentes intensidades. E assim, ao abrir seu campo interpretativo para as práticas, e assim adentrar no método genealógico, Foucault concebe o poder como um jogo entre forças presentes nas relações estabelecidas no mundo, forças essas que, “[...] devido a sua desigualdade, induzem continuamente estados de poder, mas sempre localizados e instáveis" (FOUCAULT, 1976, p. 122). Assim, o filósofo francês é obrigado a assumir o que poderíamos denominar de "ficcionalismo" e uma teoria abrangente do erro e da ilusão: no mundo do devir, nenhuma proposição pode em última instância satisfazer à condição básica posta pela concepção de conhecimento enquanto verdade - nenhuma formulação conceitual pode estar numa relação de correspondência com a realidade efetiva. Daí a recusa foucaultiana da existência de um mundo teórico puro, pois este, no limite, nada mais é do que efeito do mundo prático, ou, em outros termos, um efeito das relações de poder. Ao deslocar o foco de sua crítica para a origem prática dos discursos, o genealogista nos aponta para o erro intelectual que subjaz a esta motivação: a crença de um fundamento puramente teórico na produção da verdade, independente do interesse prático.

O poder, portanto, não é “[...] efeito, em termos de causalidade, de uma instância outra” (FOUCAULT, 1976, p. 125), nem possui um ponto de vista externo ao mundo que possa ser a medida de sua representação - como conflito imanente, o poder exige a pressuposição recíproca entre as relações de forças e seus efeitos concretos:

Nenhum recurso fundador, nenhuma fuga em uma forma pura, está aí sem dúvida um dos pontos mais importantes e mais contestados desse procedimento histórico-filosófico: se ele não quer oscilar nem numa filosofia da história, nem numa análise histórica, ele deve se manter no campo de imanência das singularidades puras. (FOUCAULT, 1990, p. 50).

Imanência, portanto, entre as forças que compõem as relações de poder, e o que Foucault denomina "práticas discursivas e não-discursivas": dois campos que formam uma única rede de relações das quais surgem mecanismos que as regulam e as modificam. Diante de pressupostos que impõem ao pensamento filosófico cenário tão instável e fragmentado, como é possível concretizar esse método que Foucault denomina de "prática histórico-filosófica"? Não pretendemos desenvolver essa questão em sua toda sua complexidade aqui; porém, para avançarmos no problema, observemos, por exemplo, como Foucault descreve o caráter de suas investigações na conferência "O que é a crítica?":

Com efeito, trata-se, nessa prática histórico-filosófica, de se fazer sua própria história, de fabricar como por ficção a história que seria atravessada pela questão das relações entre as estruturas de racionalidade que articulam o discurso verdadeiro e os mecanismos de assujeitamento que lá estão ligados, questão que evidencia como os objetos históricos habituais e familiares aos historiadores deslocam-se para o problema do sujeito e da verdade com os quais os historiadores não se ocupam. (FOUCAULT, 1990, p. 45, g.n).

A definição não é exaustiva (e nem definitiva) mas nos dá um bom exemplo de como Foucault descreve um método que se desdobra, constituindo-se peça fundamental da investigação histórico-filosófica por meio de uma reflexão que não se pretende neutra, pois já nasce como uma força atuante nas relações do presente através do próprio exercício do pensamento. Suas pesquisas investigam como, em uma "estrutura de racionalidade" composta por uma rede de relações históricas, um saber (os "saberes" que interessam a Foucault, em geral, são os que possuem a forma de uma prática discursiva em que o sujeito é objetivamente determinado, passando a pertencer ao jogo do verdadeiro-falso), efetivamente funciona como um saber (por exemplo, a psiquiatria, a criminologia, os discursos sobre a sexualidade, entre outras "analíticas da finitude"), algo que, para Foucault, não pode existir senão como instrumento de dominação, como a meta de uma luta, enfim, como o exercício de um poder. No interior dos discursos de saber, cada enunciado considerado como verdadeiro 
exerce uma intensidade de força e cria ao mesmo tempo uma condição de possibilidade para o exercício de certa forma de dominação; do mesmo modo, todo exercício de poder implica ao menos um "mecanismo de assujeitamento", uma técnica, prática não-discursiva que nasce a partir dos conflitos dessas relações de forças que se manifestam em determinado momento. Essas conexões operam "[...] uma neutralização quanto aos efeitos de legitimidade" (FOUCAULT, 1990, p. 48), tornando determinadas formas de dominação "aceitáveis" ao produzirem valores de modo sistemático. Assim, o projeto foucaultiano perpassa por essas redes de relações onde se articulam formas de produção de saberes e mecanismos de poder como um denunciante de tudo aquilo que tende a imobilizar o sujeito em posições naturalizadas, em suas condições de aceitabilidade de aprisionamentos. Nessa mesma conferência de 1978, Foucault dá à sua prática de pensamento o nome de “[...] prova de acontecimentalização” (épreuve d'événementialisation):

O que eu entenderia por procedimento de acontecimentalização [...] seria isso: inicialmente tomar conjuntos de elementos onde se pode localizar em primeira aproximação, portanto, de modo integralmente empírico e provisório, conexões entre mecanismos de coerção e conteúdos de conhecimento. (FOUCAULT, 1990, p. 47).

Trata-se de avaliar um "acontecimento" como um campo momentâneo, fragmentado, espontâneo e, principalmente, sem um objeto pré-estabelecido e sem a busca de uma causa que dê sentido a uma continuidade no tempo. Um campo de forças que "não estava inscrito em nenhum a priori” (FOUCAULT, 1990, p. 50), como uma rede de relações que constituem uma linha de inteligibilidade calculável, uma "grade de análise" (FOUCAULT, 1990, p. 49) sustentada por uma multiplicidade de focos de lutas, de embates de forças, de relações de saber-poder que jamais formam uma malha conservadora no corpo social pois repelemse, atraem-se e assim alteram suas intensidades. E, se tratamos de intensidades, falamos também em constituição de diferenças, de singularidades de forças que são constantemente redistribuídas nos jogos históricos dessas relações:

O que se procura então não é saber o que é verdadeiro ou falso, fundamentado ou não fundamentado, real ou ilusório, científico ou ideológico, legítimo ou abusivo. Procurar-se saber [...] o que faz com que tal elemento de conhecimento possa tomar efeitos de poder afetados nesse sistema como um elemento verdadeiro ou provável ou incerto ou falso, e o que faz com que tal procedimento de coerção adquira a forma e as justificações próprias a um elemento racional, calculado, tecnicamente eficaz, etc. (FOUCAULT, 1990, p. 48).

Portanto, é preciso superar o que nos é dado e recuperar um conteúdo ativo e fecundante das relações nas quais os sujeitos estão envolvidos: daí a importância da força das interpretações foucaultianas, que devem sempre ser entendidas como componentes de emergência, como instrumento de luta ou, para usarmos seu vocabulário, como uma "caixa de ferramentas". Por essa razão Foucault procura descrever a instauração do campo saber-poder no "feixe da experiência do real”, em uma estratégica que consiste em expor o contexto histórico a partir do qual surgiram e se fixaram as crenças em torno da relevância prática das representações teóricas, assim como das técnicas que atuaram no estabelecimento destas crenças. Seu ponto de vista localiza-se sempre em uma espécie de "passo anterior", como um retorno possível às condições e efeitos dos termos dessas relações que emergem como forças positivas na história e constituem “estruturas de racionalidade”. Análise não só de seus termos, mas também do modo como as relações operam umas com as outras: "[...] são relações que estão em perpétuo destacamento umas em relação às outras” (FOUCAULT, 1990, p. 51). Nesse ponto torna-se evidente uma das razões dos pressupostos de Foucault: recusando uma busca pela causa ou gênese do poder em favor de uma interpretação crítica de um conjunto de relações é possível avaliá-lo não somente como um mecanismo de "repressão", cuja força negativa e estática vem "de cima”, mas como um modelo dinâmico, produtor de "positividades" por todo campo social. Poder que não somente proíbe ou opera a partir do binômio repressor-reprimido, mas que principalmente atua, regula, modifica, fabrica, perpetua-se. Trata-se, portanto, de ter como pressuposto a ideia de que essas relações são compostas por linhas de rupturas aleatórias cujo difícil trabalho de interpretação é fundamental: 
O reconhecimento da aceitabilidade de um sistema é indissociável do reconhecimento do que o tornava difícil de aceitar: sua arbitrariedade em termos de conhecimento, sua violência em termos de poder, sua energia. (FOUCAULT, 1990, p. 50).

Desde seus pressupostos a filosofia de Foucault nos revela a impossibilidade de se resolver a tradicional questão do "acesso à verdade" ou da "legitimidade política" em sua generalidade, pela inspeção direta de uma essência, em favor de um projeto que nos apresenta estratégias de visibilidade desses jogos de poder nos quais estamos inseridos em nossa atualidade. Importante mencionar que a essa altura de nossa exposição é necessário resistirmos a duas tentações: a primeira, a de reduzir a obra de Foucault a uma mera demolição de saberes totalitários, e, a segunda, a de associarmos suas pesquisas a uma abdicação diante do relativismo e da multiplicidade das formas históricas. Para escaparmos dessas conclusões precipitadas, é preciso antes entender como sua perspectiva abre um campo para duas operações complementares: a) a circunscrição dos efeitos previsíveis desse campo das relações de saber-poder que, articuladas e localizadas em algum ponto singular da história, constituem parte do nosso presente; e, a mais relevante, b) a exposição das estratégias que os sujeitos podem assumir no corpo social, em um exercício de construção da melhor localização entre as posições possíveis nesse mapa das lutas reais que é iluminado pela prática histórico-filosófica: “[...] trata-se de pensar sempre de tal maneira que nós o vejamos (o poder) associado a um domínio de possibilidade e por consequência de reversibilidade, de inversão (renversement) possível." (FOUCAULT, 1990, p. 52). Vários equívocos sobre a filosofia de Foucault poderiam ser poupados pela simples atenção à diferença e à complementaridade entre estas duas operações: a recusa da busca pelos universais não implica uma desqualificação absoluta, mas impõe uma estratégia local fundada numa método que percorre a história da "verdade" e das "práticas" como um jogo de forças e de busca por dominação que deve ser atravessado e transgredido com o fim de lançar luz a uma rede que funciona de forma supostamente neutra, viabilizando, assim, a possibilidade de criação de outras formas de vida e de pensamento. Daí a insistência de Foucault em afirmar que o "tema central" de suas pesquisas é justamente a questão do "sujeito" (FOUCAULT, 2001, p. 1042), seus diferentes modos de constituição enquanto ponto de emergência do campo saber-poder. É esse problema que emerge como ponto de partida geral para investigações sustentadas por essa prática do pensamento que caracteriza a filosofia foucaultiana, uma atitude última de não querer ser governado de determinada maneira:

A questão seria antes esta: como a indissociabilidade do saber e do poder no jogo das interações e das estratégias múltiplas pode induzir ao mesmo tempo singularidades que se fixam a partir de suas condições de aceitabilidade e um campo de possíveis, de aberturas, de indecisões, de retornos e de deslocamentos eventuais que os tornam frágeis, que os tornam impermanentes, que fazem desses efeitos dos acontecimentos nada mais, nada menos que acontecimentos? De que modo os efeitos de coerção próprios a essas positividades podem ser, não dissipados por um retorno ao destino legítimo do conhecimento e por uma reflexão sobre o transcendental ou o quase transcendental que o fixa, mas invertidos ou desfeitos no interior de um campo estratégico concreto que os induziu, e a partir da decisão precisamente de não ser governado? (FOUCAULT, 1990, p. 53).

Foucault identifica na decisão de não ser governado o ponto de partida de suas pesquisas genealógicas. No entanto, essa vontade não é tratada por ele como uma vontade ideal que deve ser universalizada por sua origem adequada a uma lei moral anterior. Pelo contrário, é preciso empreender uma genealogia dessa vontade de não ser governado para conhecermos as forças que estavam em jogo em sua emergência histórica.

\section{II}

Percorremos brevemente a maneira como Foucault interpreta parte de seu pensamento para abordamos agora o modo como ele articula sua filiação à tradição da Aufklärung. Em um primeiro momento essa associação pode provocar certo incômodo - não era Foucault um denunciante dos jogos de saber-poder nos 
quais supostamente também se localiza o conjunto de teorias vinculadas ao movimento que conhecemos como Iluminismo? Sua prática filosófica não tinha como pressuposto questionar toda forma de pensamento que se ocupa com a questão da gênese do conhecimento e da busca pela determinação de objetividade? Aqui é preciso seguir a lição de Foucault e desconfiar de conclusões generalizáveis e imediatas. Passemos então a expor como Foucault distingue com precisão as diferenças entre os conceitos de "Aufklärung" e “crítica” em Kant na conferência “O que é a Crítica?”. Antes, porém, é necessário notar que no mesmo ano da conferência Foucault ministra no Collège de France o curso "Segurança, território e população”, apresentando, grosso modo, uma genealogia da "governamentalidade", compreendida então como um conjunto de técnicas de "governo da população" (FOUCAULT, 2004, p. 111), uma “arte de governar os homens" tipicamente moderna, cuja dinâmica das relações remete às práticas do poder pastoral e suas técnicas de obediência pela salvação ${ }^{4}$ É preciso, portanto, ter em mente que Foucault estava imerso na questão do "governo da população" e seus desdobramentos ao analisarmos, no texto da conferência, o modo como ele traduz o problema da Aufklärung não como questão teórica, mas como um problema prático, como uma "atitude crítica” que questiona esse dever de obediência.

Com a “explosão da arte de governar” (FOUCAULT, 1990, p. 47) a partir do século XV, tanto em relação a um processo histórico de transformações das práticas de governo quanto em sua extensão para outras áreas do corpo social (educação, família, saúde pública, etc.), a busca pela resistência a essas formas de governo também ampliará seu espaço:

[...] uma questão perpétua que seria: "como não ser governado assim, por isso, em nome desses princípios, em vista de tais objetivos e por meio de tais procedimentos, não dessa forma, não para isso, não por eles”; e se nós damos a esse movimento da governamentalização, da sociedade e dos indivíduos ao mesmo tempo, a inserção histórica e a amplitude que creio ter sido a sua, parece que poderíamos aproximadamente colocar ali o que chamaríamos de atitude crítica. (FOUCAULT, 1990, p. 38).

Desse modo Foucault localiza de maneira geral uma das origens da "atitude crítica", essa "forma de cultura geral" que deve ser compreendida como um contraponto ao processo histórico de extensão dessas "artes de governo", ou seja, como uma "maneira de desconfiar delas, de recusá-las, de limitá-las, de encontrar uma justa medida, de transformá-las, de procurar escapar”. "Atitude crítica” que, em termos históricos, seja de ordem religiosa (reinterpretações das Escrituras para questionar uma já estabelecida), jurídica (direito natural como limite ao governo) ou científica (produção de novas verdades) (FOUCAULT, 1990, p. 38-39), refere-se sempre a uma resistência, à construção de uma nova força que questiona esses "feixes de relações" que amarram "o poder, a verdade e o sujeito": "[...] o movimento pelo qual o sujeito se dá o direito de interrogar a verdade sobre seus efeitos de poder e o poder sobre seus discursos de verdade" (FOUCAULT, 1990, p. 38-39). É justamente esse exercício, essa "coragem" de estabelecer um limite e não querer ser governado de determinado modo, que Foucault encontra na definição que Kant dá a Aufklärung no texto “Resposta à pergunta: o que é Aufklärung?”, de 1784. "Saída da menoridade”, portanto, como uma prática de questionamento da obediência a qualquer forma de governo que não seja questionado em seus limites, exercício que, nos termos de Kant, "nada mais se exige senão liberdade" (KANT, 1985, p. 104).

A compreensão do modo como Kant define liberdade no opúsculo em questão é inseparável de uma proposta de reforma (e não revolução) do pensamento, como interpreta Rubens Rodrigues Torres Filho. Ao reformular a pergunta original e pôr em questão - Quem é o esclarecimento? - Rubens Rodrigues encontra, no próprio texto kantiano, uma resposta fundamentada no poder: “[...] é o Século de Frederico” (TORRES FILHO, 2004, p. 88), convergindo, assim, com a leitura de Foucault. Argumenta Rubens Rodrigues que a distinção do uso da razão entre público e privado dá a Kant a possibilidade de solucionar 
o problema da Aufklärung pela noção transcendental de limite: a liberdade civil, vinculada ao uso privado da razão, garante que o cidadão jamais deve deixar de obedecer às regras que regem seu ofício, enquanto a liberdade de pensamento ou de espírito, essa sim ilimitada, refere-se ao sujeito como membro da "sociedade cosmopolita", que fala em nome próprio e que pode livremente raciocinar e dialogar com o "público". No entanto, a artimanha de Kant está em somente tornar possível na prática essa distinção entre liberdade civil e de pensamento por meio mediação do "[...] único senhor capaz de pronunciar aquela voz de comando" (TORRES FILHO, 2004, p. 88), o príncipe que governa e assume sua condição de garantidor da tendência racional da humanidade em direção à autonomia plena. Nesse sentido, Rubens Rodrigues habilidosamente revela que a definição transcendental de Aufklärung, antes de ser a mera passagem da heteronomia à autonomia, contém um fundamental posicionamento político de Kant: "[...] a Ilustração se decide em outro território, onde não se põe a questão da obediência civil” (TORRES FILHO, 2004, p. 87), ou, nos termos de Foucault, trata-se da expressão de um desejo de ser governado de determinado modo e não de outro, de questionar um modo de ser e assim praticar certa crítica das formas de governo que as condições históricas do século das Luzes tornou possível 5 .

Interessante notar como Kant invoca em seu texto as figuras do oficial, do financista e do sacerdote como exemplos de autoridades, imagens que não somente correspondem a um conjunto de formas de governo, mas que também se vinculam a formas de saber como instrumentos para o exercício desse poder. São as escolhas dos exemplos de Kant que direcionam os exemplos históricos acima mencionados dessa breve genealogia foucaultiana da Aufklärung: "[...] é característico que, nesse texto sobre a Aufklärung, Kant dá como exemplos de conservação da menoridade da humanidade [...] precisamente a religião, o direito e o conhecimento" (FOUCAULT, 1990, p. 40), campos do uso privado da razão, onde a menoridade não deve ser eliminada abruptamente, mas deve antes respeitar o longo processo de emancipação previsto na definição transcendental da razão. "Atitude crítica", portanto, que nasce de um enfrentamento contextualizado no interior dessas lutas contra os processos de "governamentalidade", como um exercício crítico que via a construção de um espaço de questionamento sobre como se dão as relações de poder em determinado momento.

Descrita o que é a Aufklärung para Foucault, passemos a analisar como ele expõe a passagem da Aufklärung a outra forma de crítica, aquela a qual Kant efetivamente engajou-se:

[...] Com relação a essa Aufklärung, como se poderia situar a crítica, propriamente dita? [...] Eu diria, e aqui estão coisas completamente infantis, que, em relação à Aufklärung, a crítica será aos olhos de Kant o que ele dirá ao saber: você sabe bem até onde pode saber? Raciocine tanto quanto você quer, mas você sabe bem até onde pode raciocinar sem perigo? A crítica dirá, em suma, que é menos no que empreendemos, com mais ou menos coragem, do que na ideia que nós nos fazemos do nosso conhecimento e de seus limites, aí está a nossa liberdade, e que, por consequência, no lugar de deixar ser dito por um outro "obedeça", é nesse exato momento, quando se terá feito do seu próprio conhecimento uma ideia justa, que poderemos descobrir o princípio da autonomia e que não teremos mais que escutar o "obedeça"; ou ainda que o "obedeça" será fundado sobre a autonomia mesma. (FOUCAULT, 1990, p. 41).

A interpretação de Foucault estabelece uma relação entre filosofia crítica e Aufklärung, tratando a primeira como efeito da segunda e indicando assim a anterioridade ética e política da crítica. A atitude de "não querer ser governado de tal modo", ou seja, certa desconfiança com o modo como o sujeito era objetivamente determinado pela tradição metafísica (e certamente com as implicações éticas e políticas das conclusões da "rainha das ciências"), conduziu Kant em seu projeto de determinação do uso adequado da razão, movimento necessário para que uma filosofia transcendental pudesse ser criada. Paralelamente a Foucault, Gérard Lebrun também associou o trabalho da crítica a uma "atitude" que se opõe à "rotina do comportamento teórico", pois critica um modelo de acesso aos objetos da experiência que não havia se questionado sobre seu fundamento até então: "Sem o surgimento da atitude crítica [...] a razão jamais 
pensaria em delimitar o campo da experiência, isto é, aperceber-se, na condição de razão teórica, como limitada pelo supra-sensível entendido de maneira positiva” (LEBRUN, 2001, p. 73). A crítica kantiana, enquanto exercício que interroga o alcance da verdade e portanto o alcance do poder, é compreendido então como uma atitude que figura no centro da própria filosofia transcendental enquanto consciência que proíbe a extensão infinita do conhecimento:

[...] isto o simples comportamento teórico jamais nos teria ensinado: enquanto está engajada no uso teórico, 'encerrada no interior do mundo sensível', a razão desconhece inteiramente essa limitação da experiência que é, no entanto, a tarefa primordial que lhe incumbe. (LEBRUN, 2001, p. 73).

Tomar a crítica como atitude é afirmar uma prática antidogmática se propõe o dever de determinar a limitação da experiência a partir de um exame do uso adequado da razão. Trata-se de movimento que, compreendido a partir do funcionamento da própria filosofia foucaultiana, prevê que uma atitude crítica diante do uso da razão também será necessariamente um projeto de limitação de técnicas de dominação, pois seu efeito no campo dos saberes cria limites nos instrumentos de poder.

Obviamente Foucault não interpreta a crítica kantiana como um convite a um absoluto governo de si: “[...] seria fácil mostrar que para ele a autonomia está longe de ser oposta à obediência aos soberanos” (FOUCAULT, 1990, p. 41), e seria precipitado afirmar que Foucault compartilha os mesmos pressupostos transcendentais de Kant (talvez nisso esteja seu cuidado em diferenciar "Aufklärung" e "crítica"); o que importa então é mostrar como Kant reorganizou o pensamento filosófico ao destacar a relevância de se pensar a partir dessa "atitude crítica": "Kant fixou para a crítica uma empresa de desassujeitamento em relação ao jogo do poder e da verdade como tarefa primordial, como prolegômeno a toda Aufklärung presente e futura, de conhecer o conhecimento" (FOUCAULT, 1990, p. 41). Ao associar Kant a uma "empresa de desassujeitamento", Foucault define a tarefa crítica como um processo que impõe à filosofia a obrigação de realizar uma constante crítica ao próprio uso da razão, ou seja, ao próprio pensar. E, assim, podemos sugerir que, para Foucault, um dos pontos fundamentais na filosofia kantiana reside na criação de uma atitude de interrogação ou desconfiança quanto aos excessos praticados pelo exercício de uma razão que, em nome da verdade, produz saberes que podem aprisionar e condicionar os sujeitos.

A Aufklärung inaugura uma nova tradição na história do pensamento na qual Foucault se vê inscrito. E não deixa de ser surpreendente que Foucault compreenda nessa mesma tradição escolas filosóficas tão díspares quanto a Escola de Frankfurt e a fenomenologia. Mesmo tomando proporções diferentes na França e na Alemanha, pois nesta última seus efeitos foram muito mais sentidos, Foucault sublinha o modo como essa questão de fundo manteve-se intacta: "[...] Em todo caso, da esquerda hegeliana à Escola de Frankfurt, houve toda uma crítica do positivismo, do objetivismo, da racionalização, da technè e da tecnicização” (FOUCAULT, 1990, p. 42), e, quanto à França:

[...] é na fenomenologia e dos problemas postos por ela que nós voltamos à questão do que é a Aufklärung. [...] pela análise $[. .$.$] de que o sentido não se constitui senão por sistemas de constrangimentos característicos da maquinaria$ significante. (FOUCAULT, 1990, p. 44).

No entanto, no mesmo movimento em que se aproxima dessas escolas ao indicar que possuem em comum o mesmo ponto de partida, Foucault também se distancia delas ao afirmar que seguiu um procedimento diferente ao da crítica de Kant. Para Foucault, o deslocamento kantiano da Aufklärung para a crítica determinou grande parte das pesquisas filosóficas realizadas desde então:

[...] procedimento de análise que é no fundo aquele que foi seguido mais frequentemente, procedimento de análise que se poderia chamar uma investigação legítima dos moldes históricos do conhecer. É em todo caso assim que um certo número de filósofos do século XVIII, é assim que Dilthey, Habermas etc., entenderam. (FOUCAULT, 1990, p. 47). 
No caso de Foucault, em oposição a todas as escolas herdeiras da crítica de Kant, a questão da Aufklärung não o deslocou a uma reflexão sobre os limites da razão ou a uma historicidade da constituição da ciência moderna, mas, como já visto acima, a uma "prova de acontecimentalização".

O processo da Aufklärung incita certa prática que, no caso de Foucault, recusa uma filosofia do conhecimento e seus problemas clássicos (o falso, o verdadeiro, o erro, a ilusão), ou mesmo uma filosofia da história, para arriscar-se em outro campo de investigação, sem transcendental e sem história teleológica. A prática histórico-filosófica foucaultiana interpreta as relações de saber-poder a partir de um método genealógico, que vê em suas investigações históricas fundamentalmente um estudo sobre os devires que compõe o nosso presente. "Ontologia crítica de nós mesmos" (FOUCAULT, 2001, p. 1396), portanto, como resposta à vontade histórica de não querer de tal forma ser governado.

\title{
III
}

Nos textos de 1984 a questão da Aufklärung ganha outro relevo, novas interpretações que, antes de formarem uma releitura substituta daquela proposta em 1978, aparecem como outro modo de apropriação do texto de Kant, mais próximas dos problemas que Foucault abordou a partir da década de 80. Ele nos apresenta então um novo ponto de reflexão sobre sua prática filosófica: o problema anterior da "atitude crítica" conduziu seu pensamento a um outro exercício, intrínseco ao problema de "não querer ser governado" e vinculado à importância de se engajar em uma reflexão sobre a "atualidade", de se criar uma "atitude" diante do presente. Ao responder à questão "o que é a Aufklärung?", Kant torna o pensamento filosófico indissociável da tarefa de se traduzir a atualidade, estado-do-mundo provisório e intermitente que torna possível o aparecimento das diferentes formas de governo em prática no presente. Encontrar, a partir da história dessas singularidades múltiplas, as dinâmicas das relações de força que têm como efeito a nossa própria atualidade discursiva: o que é esse acontecimento no qual vivemos? Como posso, diante desse fluxo histórico, compreender determinado acontecimento e atribuí-lo um sentido, um valor? Essa questão fundamental para a filosofia moderna, que, aos olhos de Foucault (2001, p. 1387), une "[...] de Hegel a Horckheimer ou a Habermas, passando por Nietzsche ou Max Weber", foi posta em jogo pela primeira vez, nesses termos, justamente por Kant:

\begin{abstract}
A hipótese que eu gostaria de desenvolver é de que esse pequeno texto encontra-se de algum modo na dobradiça (charnière) da reflexão crítica e da reflexão sobre a história. É uma reflexão de Kant sobre a atualidade de seu trabalho. Sem dúvida, não é a primeira vez que um filósofo expõe as razões que ele tem para empreender sua obra em tal ou tal momento. Mas me parece que é a primeira vez que um filósofo liga assim, de modo estreito e a partir do interior, a significação de sua obra em relação ao conhecimento, uma reflexão sobre a história e uma análise particular do momento singular em que ele escreve e à causa da qual ele escreve. A reflexão sobre "hoje" como diferença na história e como motivo para uma tarefa filosófica particular me parece ser a novidade desse texto.
\end{abstract}

O recurso ao problema da atualidade aponta para um novo modo de se pensar, que já entende o pensamento como prática: uma "atitude" própria daquilo que Foucault denomina de modernidade (FOUCAULT, 2001, p. 1387). Foucault então nos apresenta, nos dois textos que tomamos como referência, duas diferentes perspectivas que a questão da filosofia do presente pode assumir em Kant. Uma delas desenvolve a hipótese de que a resposta à questão "O que é a Aufklärung?" também ocupou Kant anos mais tarde, em 1798, na dissertação sobre o Conflito das faculdades: "Ele vai colocá-la novamente e tentará respondê-la a propósito de outro acontecimento ao qual também não cessou de interrogar-se sobre ele mesmo. Este acontecimento, evidentemente, é a Revolução Francesa” (FOUCAULT, 2001, p. 1501). É preciso destacar como o argumento de Foucault novamente estrutura-se na ideia fundamental de "acontecimento", mas agora enquanto criação de um signo. Ao examinar o conflito entre as faculdades de direito e filosofia, Kant sintetiza-o de modo que se torna necessário saber se existe um "progresso constante 
no gênero humano", ao qual ele julga justamente ser preciso estabelecer a causa. Assim, Kant parte de um pressuposto que vincula sua busca à procura de um "acontecimento" que revele como essa causa opera seus efeitos: "[...] a atribuição de uma causa não poderá nunca determinar os efeitos possíveis, ou mais exatamente a possibilidade do efeito, mas a realidade de um efeito somente poderá ser estabelecida pela existência de um acontecimento" (FOUCAULT, 2001, p. 1502, g.n.). Isolar certo acontecimento, portanto, significa partir de seus efeitos para então imputar nele o "valor de um signo", ou seja, criar um novo significado para determinada representação que, neste caso, deve ser capaz de evidenciar a existência de uma razão permanente e universal como condição para o progresso da humanidade.

Foucault chama-nos a atenção para o tipo de operação proposta por Kant: ao afirmar que a Revolução em si não é um "acontecimento", mas sim o "entusiasmo" que ela provoca naqueles que a assistem, Kant recusa o protagonismo do processo revolucionário e de seus transtornos institucionais, transferindo-o ao sentimento que a Revolução provocou em seus espectadores, único elemento digno de ser o "signo" de um "acontecimento" que justifique o progresso da humanidade. Ou seja, ao olhar para seu presente, Kant calculou qual acontecimento "sem significação e valor" (FOUCAULT, 2001, p. 1503) era capaz de lhe fornecer a significação e o valor que buscava, o de uma disposição moral da humanidade ${ }^{6}$. A aprovação do público que testemunha a Revolução é o "signo" que nos revela como algo baseado na ilegalidade não pode possuir valor algum em si, mas é capaz de tornar-se legítimo e moral se entendido como um "acontecimento" capaz de produzir efeitos positivos no sentimento do povo que a presencia.

Seria então Kant, ao realizar uma procura pelo "signo" ou "valor" dos acontecimentos, um precursor da análise filosófica dos valores morais nos moldes de Nietzsche? Essa suposição não é improvável para Foucault, que associa a tradição da "filosofia do presente" a uma prática filosófica que é indistinta do exercício de interpretação do estado-do-mundo: filosofia que nega sua condição de teoria ou de representação para sugerir uma interpretação que promova novos valores por meio de uma "atitude crítica" que se questiona sobre sua atualidade. ${ }^{7}$ E, se retornamos então à conferência de 1978, veremos como o raciocínio de Foucault se completa: se decido "não ser mais governado de tal maneira", a tarefa de compreensão do presente, desse conjunto de relações de formas de racionalidade e de técnicas nas quais o sujeito está imerso, é um exercício indispensável para qualquer atividade que se pretende crítica (FOUCAULT, 2001, p. 1385). A partir dessa conclusão, Foucault mantém sua ideia anterior de que Kant inaugura então duas linhas filosóficas próprias à modernidade: a "crítica", que no texto de 1984 recebe o nome de "analítica da verdade" (FOUCAULT, 2001, p. 1506), e a "ontologia do presente", esse exercício crítico que impõe ao filósofo questionar-se: "o que é essa nossa atualidade?". "Ontologia”, portanto, que assume um caráter relacional que pressupõe uma visão de mundo dinâmica, baseada na ideia de que os termos das relações históricas serão interpretados justamente a partir das relações que os constituem.

Enfim, a segunda perspectiva que a Aufklärung como questionamento do presente assume em Kant relaciona-se diretamente com uma questão dos dois últimos volumes da História da Sexualidade: Aufklärung ou "atitude crítica" não somente como exercício de interpretação do presente e das relações que o constituem, mas também como prática que necessariamente implica uma relação do sujeito consigo mesmo, ou seja, uma relação de força cujos termos permanecem idênticos a si mesmos no processo de transformação. Se, como visto no item II, a Aufklärung é definida como "coragem" de afirmar como se quer ser governado, Foucault atenta para o modo como Kant determina o aspecto duplo desse processo de Ausgang (saída), que deve assumir caráter tanto coletivo quanto individual:

[...] Desde o primeiro parágrafo ele [Kant] nos faz notar que o homem é ele mesmo responsável por seu estado de menoridade. É preciso, portanto, conceber que ele não poderá sair dele a não ser por uma mudança que ele próprio operará em si mesmo. De uma maneira significativa, Kant diz que essa Aufklärung tem uma "divisa” (Wahlspruch): 
ora, a divisa é um traço distintivo pelo qual nós nos fazemos reconhecer; é também uma regra que nos damos a nós mesmos e que propomos aos outros. E qual é essa regra? Aude saber, "tenha coragem, a audácia de saber". É preciso, portanto, considerar que a Aufklärung é ao mesmo tempo um processo em que os homens fazem parte coletivamente e um ato de coragem a se efetuar pessoalmente. Eles são ao mesmo tempo elementos e agentes do mesmo processo. Podem ser seus atores na medida em que são parte dele; e ele se produz na medida em que os homens decidem ser seus atores voluntários. (FOUCAULT, 2001, p. 1384).

Em comparação a outros textos que Kant consagra à história, de fundo teleológico, a história em "Resposta à pergunta: o que é a Aufklärung?" relaciona-se a uma "reflexão sobre o "hoje" como diferença e como motivo para uma tarefa filosófica particular" (FOUCAULT, 2001, p. 1387), algo que transita entre uma filosofia da ação e dos valores. Assim Kant interpreta a saída da menoridade como um processo em que o sujeito assume responsabilidades, como se cada indivíduo, independentemente da coletividade a qual pertence, fosse responsável pelo estado de obediência em que se encontra. E, se esse sujeito deseja efetivamente alcançar sua autonomia, não deve esperar pela ação de qualquer outro a não ser dele mesmo. Aquilo que entendemos como modernidade, portanto, antes de ser uma categorização prévia de um período histórico, passa a ser definida por Foucault como uma atitude crítica de querer a própria saída da menoridade por meio de uma relação de si para si: "Por atitude, quero dizer um modo de relação no que concerne a sua atualidade; uma escolha voluntária que é feita por alguns; enfim, uma maneira de pensar e de sentir, uma maneira também de agir e de se conduzir" (FOUCAULT, 2001, p. 1987). Para Foucault, esse novo modo de agir enquanto prática definidora daquilo que se entende por modernidade é o ponto de articulação entre Kant e Baudelaire: trata-se de um tipo de relação entre criação de formas de vida (criação de um ethos a partir das práticas de si) e incorporação de discursos pelo sujeito ("tenha coragem, a audácia de saber"). Tal problemática é tratada ainda no curso ministrado por Foucault no Collège de France no mesmo ano da publicação dos artigos "Qu'est-ce que les Lumières?", momento em que as relações entre criação de formas de vida e produção de discurso verdadeiros são objeto de sua atenção. Assim, ao investigar o lugar no cinismo na cultura ocidental, Foucault se interessa pela forma de vida dos cínicos, definida então como uma "[...] depuração da vida como maneira de constituir, no próprio corpo, o teatro visível da verdade" (FOUCAULT, 2009, p. 168-169). Não se trata, portanto, de manifestação de um individualismo, de uma afirmação de si, mas de um modo de se relacionar com a verdade e de se viver a vida verdadeira por meio da redução de si ao elementar da existência. E esse tipo de relação entre forma de vida e produção de verdade Foucault também encontra na arte moderna, quando "a obra de arte ela própria, é uma maneira de retomar, sob uma outra luz, sob um outro perfil, com uma outra forma, esse princípio cínico da vida como manifestação de ruptura escandalosa, pela qual a verdade vem à tona, se manifesta e toma corpo" (FOUCAULT, 2009, p. 173), tendência que Foucault encontra de "Manet a Francis Bacon, de Baudelaire a Samuel Beckett ou Burroughs" (FOUCAULT, 2009, p. 174).

Não nos cabe aqui desenvolver a relação entre Foucault e o cinismo, interessa-nos somente destacar o modo como as relações de si na modernidade contêm uma maneira refletida de relacionar discurso já dito com a singularidade da verdade que nele se afirma a partir de uma livre escolha desses exercícios pelo sujeito. Foucault localiza no tipo flâneur de Baudelaire um colecionador, um observador da vida urbana que se apropria do meio em que vive para construir um estilo por meio de exercício que, aos poucos, limita e dá consistência ao erguer um edifício coerente para o sujeito a partir do que ele adquiriu em sua vivência com o presente: observações, leituras, anotações, repetições. Esses exercícios conferem aos sujeitos uma forma, um conteúdo para seu corpo: trata-se menos de uma regra, ou seja, de uma prescrição a ser observada severamente, do que de uma arte de viver que transforma a própria vida em acontecimento, em uma obra que deve ser bela e boa a partir de modalidades de ação que implicam também uma liberdade de escolha daquele que se utiliza dela, assim como a particularidade das circunstâncias que determinam o seu uso. A partir dessa definição o exemplo de Baudelaire como alguém que compreendeu e praticou essa 
atitude moderna torna-se um pouco mais evidente: sua definição de pintor moderno como aquele que transfigura o mundo ao exercer sua liberdade de imaginação (FOUCAULT, 2001, p. 1389) envolve tanto uma relação do sujeito com a sua atualidade a partir de uma escolha de atribuição de valores ao mundo quanto uma relação do sujeito consigo mesmo que irá incorporá-los, no caso de Baudelaire, como um dândi que se toma como objeto, e, em um só gesto, distancia-se de si e aplica sobre si suas experiências, compondo, assim, a unidade de um estilo.

Se Foucault descreve Baudelaire como poeta que exerceu essa prática de si ao se inventar como artista, conclui-se que Foucault vê em Baudelaire um herdeiro do "cuidado de si" grego, como descrito nos volumes $O$ uso dos prazeres e $O$ cuidado de si? Seria a atitude de modernidade uma espécie de renascimento de determinadas práticas da antiguidade? Para afastarmos a ingenuidade dessa hipótese, basta tomarmos o modo como Foucault se utiliza do texto de Kant para refletir sobre sua própria prática filosófica: como buscamos destacar, para Foucault a saída da menoridade kantiana relaciona-se principalmente a um pensamento crítico que interpreta a filosofia como forma desmontagem das técnicas de poder que imobilizam o sujeito e seu pensamento. É preciso, portanto, desatar esse entrelaçamento entre formas de verdade e técnicas de dominação para que outra vida seja possível, exercício filosófico que exige uma atitude crítica de construção de novos valores em relação a si e ao mundo. Assim, a filosofia só existe quando é provocada pelo mundo, ou, como descrito em $O$ uso dos prazeres: "[...] é esta a tarefa de uma história do pensamento por oposição à história dos comportamentos ou das representações: definir as condições nas quais o ser humano 'problematiza' o que ele é, e o mundo no qual ele vive" (FOUCAULT, 2013, p. 10-11). Engajar-se em uma investigação genealógica sobre os diferentes modos como o sujeito relacionou-se consigo mesmo significa, portanto, abrir um campo histórico que revele uma nova forma de se pensar a filosofia como "problematização" do mundo como ele é, em seu fluxo instável e coberto por singularidades, a partir dos meios pelos quais o sujeito apreendeu e aplicou esses "problemas" em si mesmo. Os gregos e Baudelaire, portanto, não compartilham do mesmo universo histórico e não se comunicam a partir de uma linha lógica temporal: para se chegar a tal conclusão, basta um breve olhar ao cuidado com a diferença entre o vocabulário que Foucault aplica em cada uma dessas pesquisas. No entanto, se pensarmos os dois elementos como "acontecimentos" que conectam uma matriz de relações da experiência do sujeito enquanto aquele que aplica determinadas técnicas sobre si a partir de seu contato imediato com o mundo (e com os discursos verdadeiros que ele decide aplicar a si), então é possível afirmar que as técnicas de si dos antigos e de Baudelaire pertencem à mesma linha genealógica:

[...] a crítica vai se exercer não mais na procura das estruturas formais que têm valor universal, mas como pesquisa histórica através dos acontecimento que nos levaram a nos constituir, a nos reconhecer como sujeito do que fazemos, pensamos, dizemos. Nesse sentido, essa crítica não é transcendental e não tem como fim tornar possível uma metafísica: ela é genealógica em sua finalidade e arqueológica em seu método. Arqueológica - e não transcendental - no sentido de que ela não procurará apreender as estruturas universais de todo conhecimento ou de toda ação moral possível, mas tratar dos discursos que articulam o que nós pensamento, dizemos e fazemos como acontecimentos históricos. E essa crítica será genealógica no sentido de que ela não deduzirá da forma do que somos o que para nós é impossível fazer ou conhecer; mas ela apreenderá da contingência que nos fez ser o que nós somos a possibilidade de não mais ser, fazer ou pensar o que nós somos, fazemos ou pensamos. (FOUCAULT, 2001, p. 1389).

IV

Analisamos como Foucault apropriou-se do texto de Kant para lhe conferir um significado próprio, interpretando a questão da Aufklärung e da modernidade como uma "atitude crítica" ao afastá-la da teoria pura em favor de uma concepção prática do pensamento. A partir dessa perspectiva prática, Foucault nos apresenta uma rica reflexão sobre sua filosofia, descrevendo-a, em resumo, como uma análise de campos determinados 
da história que envolvem as diferentes formas de relações de saber-poder-sujeito, sempre tomando como pressuposto o caráter contingente e singular desses acontecimentos. Foucault então se identifica como um praticante da "atitude crítica" inaugurada por Kant, pois suas genealogias necessariamente procuram "saídas da menoridade" ao interpelarem relações que aprisionam o sujeito para que outros modos de reflexão e de formas de vida sejam viáveis. Assim, o exercício dessa prática-filosófica reivindica uma a) "atitude crítica" como coragem de se opor às práticas de governo vigentes, atitude que sugere uma espécie de retorno à vocação questionadora da filosofia. Trata-se de algo que demanda do filósofo uma b) "atitude crítica" como exercício de interpretação da atualidade, referência fundamental para o diagnóstico e a questionamento dos valores do presente, e uma c) "atitude crítica" como prática de si, ou seja, como conjunto de técnicas criadoras de formas de vida que produzem efeito reflexivo e inventivo, em um processo de governo de si que envolve tanto domínio quanto coragem de transformar a própria vida em objeto de manifestação de certa verdade.

\section{NOTAS}

1. Agradeço as leituras e as discussões sobre o artigo no âmbito do Grupo de Pesquisa Michel Foucault (PUC-SP), fundamentais para o amadurecimento dos argumentos.

2. Uma breve observação: quando Foucault volta-se ao plano arqueológico, avaliando somente as condições de possibilidade de nascimento de formas de discurso ao longo da história, Kant aparece como um "acontecimento" fundamental na reorganização dos saberes na episteme moderna. E nos parece que é a partir de uma radicalização do kantismo que determinadas formas de positividades no campo das ciências humanas puderam acontecer: "O trabalho, a vida e a linguagem aparecem como tantos "transcendentais", que tornam possível o conhecimento objetivo dos seres vivos, das leis da produção, das formas da linguagem. Em seu ser, estão fora do conhecimento, mas são, por isso mesmo, condições de conhecimentos; correspondem à descoberta, por Kant, de um campo transcendental e, no entanto, dele diferem em dois pontos essenciais: alojam-se do lado do objeto e, de certo modo, além dele; como a Ideia na Dialética transcendental, totalizam os fenômenos e dizem a coerência a priori das multiplicidades empíricas; fundam-nas, porém, num ser cuja realidade enigmática constitui, antes de todo conhecimento, a ordem e o liame daquilo que se presta a conhecer; ademais, eles concernem ao domínio das verdades a posteriori e aos princípios de sua síntese - e não à síntese a priori de toda experiência possível” (FOUCAULT, 2000. p. 336, g.n.).

3. Assim Foucault resume a exclusão da diferença na episteme moderna, momento em o "homem" passa a ser conteúdo de saberes que o determinam a partir de sua finitude: "De um extremo ao outro da experiência, a finitude responde a si mesma; ela é, na figura do Mesmo, a identidade e a diferença das positividades e de seu fundamento. Vê-se como a reflexão moderna, desde o primeiro esboço dessa analítica, inclina-se em direção a certo pensamento do Mesmo - em que a Diferença é a mesma coisa que a Identidade - exposição da representação, com sua realização em quadro, tal como o ordenava o saber clássico. [...] é á que se verá sucessivamente o transcendental repetir o empírico, o cogito repetir o impensado, o retorno da origem repetir seu recuo" (FOUCAULT, 2000, p. 434-435, g.n.).

4. "O que eu queria fazer agora [...] seria uma coisa que eu denominaria uma história da "governamentalidade" (gouvernementalité). [...] Por "governamentalidade" entendo o conjunto constituído pela instituições, os procedimentos, análises e reflexões, os cálculos e as táticas que permitem exercer essa forma bem específica, embora muito complexa, de poder que tem como algo principal a população, a economia política como forma majoritária de saber e os dispositivos de segurança como instrumento técnico essencial" (FOUCAULT, 2004, p. 111). Assim, ao interpretar os dispositivos constituídos por técnicas de governo voltadas para a "direção de conduta", Foucault privilegia o uso do termo "governamentalidade" para circunscrever um campo do poder que designa um conjunto de forças criadoras de uma nova lógica de organização da multiplicidade. Esse diagrama de relações de poder, denominado "segurançapopulação-governo", argumenta Foucault, caracteriza uma forma de governar típica da modernidade.

5. Como Rubens Rodrigues desenvolve no artigo mencionado, tal atitude crítica aparece ainda tanto no conceito de tolerância de Voltaire quanto no destino do Sobrinho de Rameau, textos onde o cinismo que nasce no pensamento 
iluminista revela seu paradoxo fundamental, também presente da fórmula foucaultiana "não desejar governado de tal modo". O cinismo das Luzes está no modo como certo pensamento que advém dela se julga livre de todo poder, de toda coação, através da crença em um universal que engloba todas as particularidades (a tolerância, a posição do Filósofo diante do Sobrinho, o uso público da razão). É o que Foucault mostra ao interpretar a Aufklärung como uma prática que busca instaurar um novo regime de verdade nas relações de força, como uma atitude de querer ser governado de outra maneira e assim reorganizar a produção dos saberes e das técnicas de poder: em outros termos, trata-se da abertura de um espaço que torna possível outra forma de governo, outro universal que reinará de outro modo. Ou, nos termos de Rubens Rodrigues: "a ilustração morde sua própria cauda e gera seu Outro, mas sem que esse Outro, por ser gerados por ela, lhe seja necessariamente dócil” (TORRES FILHO, 2004, p. 65).

6. “[...] essa disposição manifesta-se permanentemente por dois modos: primeiramente, no direito que todos os povos têm de se dar a Constituição política que lhes convêm, e no princípio conforme o direito e a moral de uma Constituição política que evite, em razão de seus princípios mesmos, toda guerra ofensiva” (FOUCAULT, 2001, p. 1504).

7. Foucault dedica-se a essa questão mais detidamente no texto originalmente publicado em inglês “[...] Mas se a questão kantiana era saber quais limites o conhecimento deve renunciar a atravessar, parece-me que, atualmente, a questão crítica deve ser revertida em uma questão positiva: no que nos é apresentado como universal, necessário, obrigatório, qual é a parte do que é singular, continente e devido a imposições arbitrárias. Trata-se, em suma, de transformar a crítica exercida sob a forma de limitação necessária em uma crítica prática sob a forma de ultrapassagem possível.” . Id., “Qu'est-ce que les Lumières? «What is Enlightenment?» (FOUCAULT, 2001, p. 1393).

\section{REFERÊNCIAS}

FOUCAULT, M. Histoire de la sexualité I: la volonté de savoir. Paris: Gallimard, 1976.

1990.

. Qu'est-ce que la critique? Bulletin de la Société Française de Philosophie, Paris, V. 84, n. 2, p. 35-63,

. As palavras e as coisas. Tradução de Salma Muchail. 8. ed. São Paulo: Martins Fontes, 2000.

. Dits et écrits. Paris: Éditions Gallimard, 2001. v. 2.

. Sécurité, territoire, population: cours au Collège de France, 1977-1978. Paris: Seuil/Gallimard, 2004.

. Le courage de la vérité, Le gouvernement de soi et des autres II: cours au Collège de France, 19831984. Paris: Seuil/Gallimard, 2009.

. Histoire de la sexualité II: L'usage des plaisirs. Paris: Gallimard, 2013.

KANT, I. Resposta à pergunta: o que é o esclarecimento? In: Textos seletos. 2. ed. Petrópolis: Vozes, 1985.

LEBRUN, G. A terceira crítica ou a teleologia reencontrada. Tradução de Rubens Rodrigues Torres Filo. In: Sobre Kant. 2. ed. São Paulo: Iluminuras, 2001.

TORRES FILHO, R. R. À sombra do Iluminismo. In: Ensaios de Filosofia ilustrada. 2. ed. São Paulo: Iluminuras, 2004. 